\title{
Changes in $\alpha$-Amylase and Protease activities in Quinoa, Amaranth, and Brown Rice according to Germination Time
}

\author{
Jung-Hwan Nam ${ }^{1}$, Soojin Park ${ }^{2}$ \\ ${ }^{1}$ Highland Agriculture Research Institute, National Institute of Crop Science Rural \\ Development Administration, \\ ${ }^{2}$ School of Food \& Nutrition Science of Bioindustry, Semyung University, \\ ${ }^{1}$ conplab@korea.kr, ${ }^{2}$ sjpark@semyung.ac.kr
}

\begin{abstract}
The present study was performed to analyze the change in the activity of starch degrading enzyme and proteolytic enzyme based on the sprouting period of quinoa, amaranth, and brown rice and understand the characteristics of germinated Andean cereals. Quinoa $(Q)$, amaranth $(A)$, and brown rice $(B)$ were germinated in water for 6 hours, each specimen was sprouted again in air for 6, 12, 24, and 48 hours and lyophilized and the water-soluble extract was used as the enzyme solution. Commercial malt $(M)$ was used as the control group. In each test group, the $\alpha$-Amylase activity increased significantly in proportion to the germination period, and that of $Q$ was the highest in the $24 \mathrm{~h}$-germinated group and that of $A$, in the $48 \mathrm{~h}$-germination group $(p<0.05)$. The $\alpha$-Amylase activity of $Q$ and $A$ was significantly higher than that of the malt and that of the B was also the highest in the 48 h-germination group but the lowest among all test groups. The protease activity also increased in proportion to the germination period, and that of both $Q$ and $A$ was significantly high in the 48 h-germination group ( $p<0.05)$. The protease activity of the Andean cereals was approximately 1.7 times that of M. In conclusion, the enzyme activity of germinated quinoa and germinated amaranth is deemed to be effective and to have efficient useful value in various food industries and bio-industries.
\end{abstract}

Keywords: quinoa, amaranth, sprouting, $\alpha$-Amylase, protease

\section{Introduction}

Germination refers to the emergence of the plumule and radicle in a plant seed. In order for plant seeds to germinate, appropriate conditions of oxygen, moisture, temperatures and light must be met, and germination requires a certain amount of time. Once plant seeds start to germinate, various enzymes contained in them begin to be activated, respiration becomes active, and metabolic responses which convert the stored nutrients of the gemmule into easy-to-use forms occur [1,2]. In general, it is known that when brown rice germinates, various enzymatic ${ }^{1}$ activities are increased, its functional ingredients and nutrients such as $\gamma$-aminobutyric acid (GABA), ferulic acid and inositol are increased, its taste is improved, its texture becomes soft, and it is made easier to digest and absorb. Studies of various physiological activities such as prevention of hypertension, anti-obesity effects, and sedative effects based on these results were reported $[5,6]$. Since $\alpha$-Amylase and protease activities of germinated-barley malt are also remarkably increased during germination, malt is used in making various food products such as beer, whiskey, and starch syrup as well as Korean traditional foods including sikhye (a

Article history:

Received (October 12, 2017), Review Result (November 3, 2017), Accepted (January 5, 2018) 
Korean traditional rice beverage), yeot (taffy), and Korean fermented soybean foods. Quinoa and amaranth are included in pseudo-cereals, which have recently received much attention. They are attracting increasing attention for the following reasons. Although these crops are not grains, they contain not only carbohydrates but also essential amino acids. In addition, since they contain unsaturated fatty acids, including phospholipids, they are food resources that can supply calories. Furthermore, they contain adequate amounts of vitamins, minerals and cellulose for human nutrition, and include all of the functional components, such as saponin, phytosterol, squalene, and polyphenol $[7,8]$. These originated in Central and South America and were staple foods during the Peruvian Inca and Mexican Aztec eras. Since they do not contain gluten, they are today used not only as ingredients of cereals and confectionery baking but also as substitute food for gluten-free diet [9]. In addition, it has been reported that germination of quinoa and amaranth significantly increases the polyphenol content such as total phenolic and anthocyanin contents and improves antioxidant activity $[7,8]$. Therefore, this study aimed to investigate the changes in the activities of starch degrading enzymes and proteolytic enzymes of quinoa and amaranth according to the germination period, to understand the characteristics of germinated Andean cereals through a comparison with changes in enzymatic activities of brown rice and malt, and to provide basic data for future studies of food processing using Andean cereals.

\section{Materials and Methods}

\subsection{Materials}

In this study, for quinoa and amaranth, the crops cultivated and harvested by farmhouses in Pyeongchang and Hongcheon, Gangwon-do in 2016 were purchased, and brown rice and malt were purchased at Nonghyup Hanaro Mart in Okcheon-dong, Gangneung-si, Gangwon-do. In order to prepare germinated grain samples, all experimental equipments were sterilized with $90 \%$ alcohol and by UV irradiation. Each grain sample was rinsed 3 times with distilled water, and the water was removed. $100 \mathrm{~g}$ of each sample were placed in a CucKoo germinator (Cuckoo Electronics, CW-5511) and sufficiently immersed in $2.5 \mathrm{~L}$ of water. Each grain sample was subjected to dry (in the air) germination after wet (soaking) germination for 6 days. The germination temperature was adjusted to the chungkukjang production mode (about $38 \sim 40{ }^{\circ} \mathrm{C}$ ) of the germinator used. For the germination period of dry (space) germination, germination was proceeded with for $6,12,24$, and 48 hours, respectively. Germination states were confirmed by the stereoscopic microscope (Nikon, SMZ800), and germinated samples were frozen in a cryogenic freezer, and then dried in a freeze dryer (OPERON, FDS-12012) for 72 hours. For the enzyme activity experiment, the samples in experimental groups (quinoa, amaranth, brown rice) and control group (malt) were each pulverized, $1 \mathrm{~g}$ of each was dissolved in $10 \mathrm{~mL}$ of $0.5 \%$ $\mathrm{NaCl}$, and extraction was performed at $20^{\circ} \mathrm{C}$ for 2 hours. The extract was centrifuged and the supernatant was stored at $-70{ }^{\circ} \mathrm{C}$ in a cryogenic freezer and used as an enzyme solution. All other standards and reagents used for analysis were purchased from Sigma-Aldrich (USA).

\subsection{Methods}

$\alpha$-Amylase Activity Measurement: $\alpha$-Amylase activity was measured by the method of Yamamoto et al. [10]. $2 \mathrm{~mL}$ of the substrate solution (1\% starch solution, $\mathrm{pH} 7.4$ ) was preheated at $40^{\circ} \mathrm{C}$ for 5 minutes, and $200 \mu \mathrm{L}$ of the enzyme solution of each sample was added to induce enzyme reaction for 20 minutes. To terminate the reaction, $3 \mathrm{~mL}$ of $1 \mathrm{M}$ TCA was used, and 1 $\mathrm{mL}$ of $0.01 \mathrm{~N}$ iodine solution was used as the coupler. Absorbance was measured at $660 \mathrm{~nm}$. 
At this time, changes in absorbance were measured at constant time intervals for 30 minutes after the initiation of the iodine-starch reaction in the mixture of the starch solution and enzyme solution. When the iodine-starch reaction absorbance was decreased by $10 \%$ for 10 minutes, it was defined as 1 unit of $\alpha$-Amylase activity.

Protease Activity Measurement: Protease activity was measured in accordance with the method of Seok et al. [11]. Using $1 \%$ casein as a substrate, $1 \mathrm{~mL}$ of the enzyme solution of each sample was added and reaction was proceeded with at $40{ }^{\circ} \mathrm{C}$ for 10 minutes. The reaction was terminated using $3 \mathrm{~mL}$ of $0.4 \mathrm{M}$ TCA. After incubation at room temperature for 30 minutes, 5 $\mathrm{mL}$ of $0.4 \mathrm{M} \mathrm{Na} 2 \mathrm{CO} 3$ and $1 \mathrm{~mL}$ of $1 \mathrm{~N}$ Folin reagent were added to $2 \mathrm{~mL}$ of the supernatant after removing precipitates from the supernatant. Then, after 30 minutes of color development, absorbance was measured at $660 \mathrm{~nm}$ for 30 minutes. Protease activity was determined by the tyrosine content of each sample reaction solution using the calibration curve using tyrosine as the standard, and when $1 \mu \mathrm{g}$ of tyrosine was produced for 1 minute, it was defined as 1 unit.

Statistical Analysis: All measurements were repeated 3 times and statistical analysis was performed using SPSS (version 18.0, package for Social Science, Chicago, IL, USA). The statistical significance test was conducted by the ANOVA test, and when there were statistically significant differences, the post-hoc test was performed by the Duncan's multiple test at $\mathrm{p}<0.05$.

\section{Results}

\section{1 $\alpha$-Amylase Activity}

Table 1 shows the $\alpha$-Amylase activities of quinoa, amaranth and brown rice. The $\alpha$-Amylase activity was significantly different according to the germination period of grains ( $p=0.000$, respectively). The $\alpha$-amylase activity of quinoa was the lowest in the $6 \mathrm{~h}$ germination group and increased in proportion to the germination period until $24 \mathrm{~h}$ and decreased again in the 48 $\mathrm{h}$ germination group $(\mathrm{p}<0.05)$. The $\alpha$-Amylase activity of amaranth showed a similar trend to that of quinoa, but it was highest in the $48 \mathrm{~h}$ germination group $(\mathrm{p}<0.05)$. The $\alpha$-Amylase activities of quinoa and amaranth were higher than that of germinated barley malt. On the other hand, brown rice showed the lowest $\alpha$-Amylase activity, and in terms of the germination period, the $\alpha$-Amylase activity of brown rice was significantly higher in the $48 \mathrm{~h}$ germination group.

\section{Table $1 \alpha$-Amylase activity of Quinoa, Amaranth and Brown rice according to germination time}

\begin{tabular}{|c|c|c|c|c|c|}
\hline $\begin{array}{l}\text { Germination } \\
\text { Time(h) }\end{array}$ & ${ }^{\dagger}$ G-Quinoa & G-Amaranth & \multicolumn{2}{|c|}{ G-Brown rice } & G-Barley \\
\hline 6 & $\S_{29.28 \pm 1.07^{\mathrm{a}}}$ & $24.88 \pm 5_{5^{\mathrm{a}}}^{0.4}$ & $\begin{array}{r}3 . \\
80\end{array}$ & $\begin{array}{r}0 . \\
42^{\mathrm{a}}\end{array}$ & $\begin{array}{c}19 . \\
80\end{array}$ \\
\hline 12 & $32.98 \pm 0.50^{\mathrm{b}}$ & $29.34 \pm 9^{b} 0.3$ & $\begin{array}{c}3 . \\
68\end{array}$ & $24^{a .}$ & \\
\hline 24 & $34.39 \pm 4^{c} 0.5$ & $30.79 \pm 1^{\mathrm{c}} 0.5$ & $\begin{array}{c}3 . \\
68\end{array}$ & $23^{0 .}$ & \\
\hline 48 & $32.71 \pm_{0^{\mathrm{b}}} 1.2$ & $37.11 \pm 5^{\mathrm{d}} 0.0$ & $\begin{aligned} 5 . & \pm \\
05 & \end{aligned}$ & $31^{0 .}$ & \\
\hline
\end{tabular}


†Germinated, †commercial product, Malt

$\S$ mean \pm SD of Unit(1 unit : $10 \%$ decrease of O.D. from $1 \%$ starch solution per 10 min) with different letters indicate significant difference $(\mathrm{p}<0.05)$

\subsection{Protease Activity}

Table 2 shows protease activity of quinoa, amaranth and brown rice. Protease activity increased in proportion with the germination period. Both quinoa and amaranth showed the lowest protease activity in the $6 \mathrm{~h}$-germination group, and the protease activity of them increased in proportion with germination time, and was significantly higher in the $48 \mathrm{~h}$ germination group. As for germinated brown rice, it showed the lowest protease activity of all grains, and although there was no significant difference in protease activity up to $24 \mathrm{~h}$, the highest protease activity was observed in $48 \mathrm{~h}$-germination group $(\mathrm{P}<0.05)$. The protease activity of 48 h-germinated Andean cereals was about 1.7 times higher than that of malt.

\section{Table 1 Protease activity of Quinoa, Amaranth and Brown rice according to germination time}

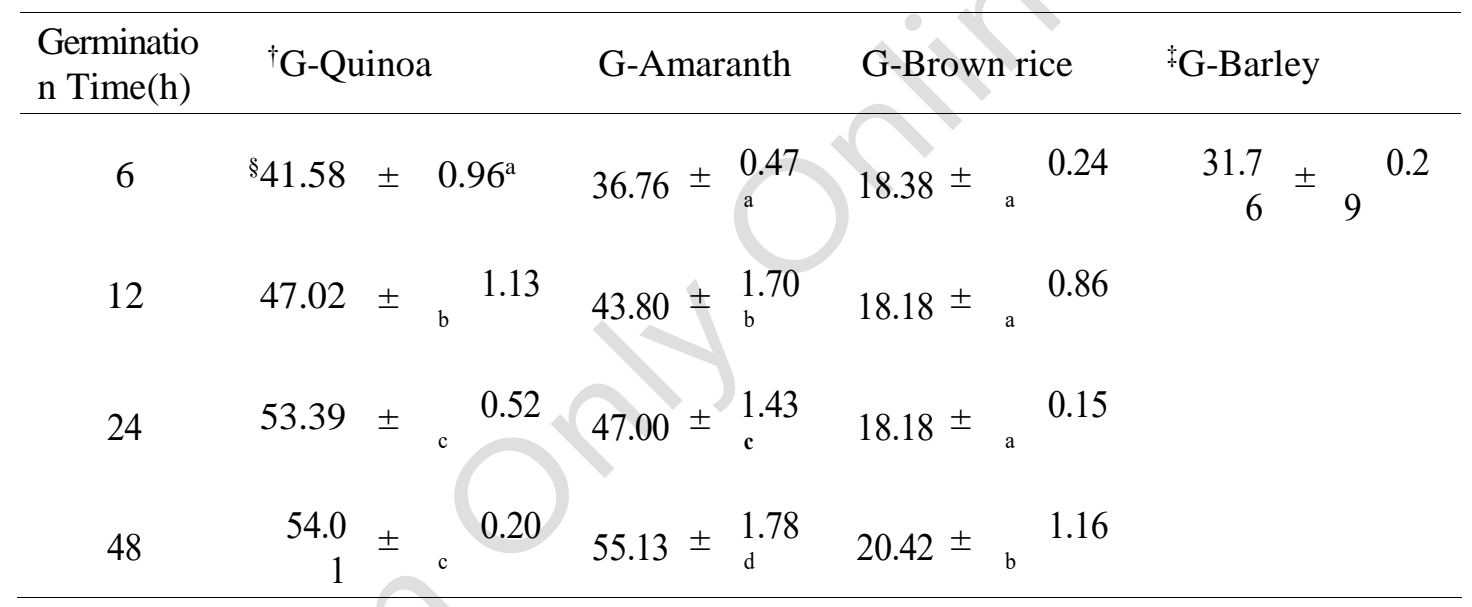

$\dagger$ Germinated, $\$$ commercial product, malt

$\S$ mean \pm SD of Unit ( 1 unit means $1 \mu \mathrm{g}$ tyrosine produce from casein per min) with different letters indicate significant difference $(\mathrm{p}<0.05)$

\section{Conclusion}

This study was conducted to compare the changes of $\alpha$-Amylase and Protease activity by using water-soluble extracts of germinated samples after germination of quinoa, amaranth and brown rice for 6 to 48 hours under the same conditions. As for quinoa and amaranth, $\alpha$-Amylase and Protease activities were significantly increased in proportion to the germination period until 48 hours of germination time, and their enzyme activities were significantly higher than that of germinated brown rice or malt. Considering the starch content and proteolytic power of quinoa and amaranth, they are considered to be very effective and efficient materials that can be applied to various food and biotech industries. This study focused on the changes in enzyme activity according to germination time, but since changes in nutritional and functional components may be affected by various germination conditions such as the germination temperature and soaking 
solution, there is a need to conduct further research for optimization of such various germination conditions. However, this study confirmed the potential utilization values of quinoa and amaranth by providing the analysis results of their enzymatic activities according to the germination period for which there have not been sufficient domestic research data available to date, and the study results of this study warrant future studies on high value-added food development and industrial application using them.

\section{ACKNOWLEDGEMENTS}

The research for this study was conducted with the financial support of the research project grant (PJ0113582017, PJ0113542017 \& PJ01349201) from the Rural Development Administration.

\section{References}

[1] http://terms.naver.com/entry.nhn?docId=1970237\&cid=50317\&categoryId=50317, Jan 24 (2018).

[2] https://en.wikipedia.org/wiki/Germination, Jan 24 (2018).

[3] D. J. Kim, S. K. Oh, J. H. Lee, M.R. Yoon, I.S. Choi , D. H. Lee and Y.G. Kim, Korean J. Food Sci. Technol. 44 (3), 300-305 (2012)

[4] H. Y. Jung, D. H. Lee, H. Y. Baek and Y. S. Lee, Korean J. Crop Sci. 53, 37-43 (2008)

[5] D. J. Kim, S. K. Oh, M. R. Yoon, A. R. Chun, I. S. Choi, D. H. Lee, J. S. Lee, R. W. Yu and Y. K. Kim, J. Korean Soc. Food Sci. Nutr. 40(6), 781-789 (2011)

[6] H. J. Kim , J. H. Lee, S. H. Choi , P. K. Kwon and M. J. Oh, J. Korean Soc. Food Sci. Nutr. 28(1), 67-73 (1999)

[7] L. Alvarez-Jubete, H. Wijingaard, E. K. Arendt and E. Gallagher, Food Chem. 119, 770-778 (2010)

[8] P. Pasko, H. Barton, P. Zagrodzki, S. Gorinstein, M. Folta, and Z. Zachwieja, Food Chem. 115, 994-998 (2009)

[9] S. Y. Hong, K. S. Cho, Y. I. Jin, Y. H. Yeon, S. J. Kim, J. H. Nam, J. C. Jeong, O. K. Kwon and H. B. Sohn, Korean J. Crop Sci. 59(1), 16-21 (2014).

[10] T. Yamamoto, I. Miyahara, S. Yamamoto, K. Fujita and K. Mizokami, J. Japanese Soc. Starch Sci. 37(3), 129136 (1990)

[11] Y. R. Seok, Y. H. Kim, S. Kim, H. S. Woo, T. W. Kim, S. H. Lee and C. Choi, Agr. Chem. Biotechnol. 37, 65-71 (1994)

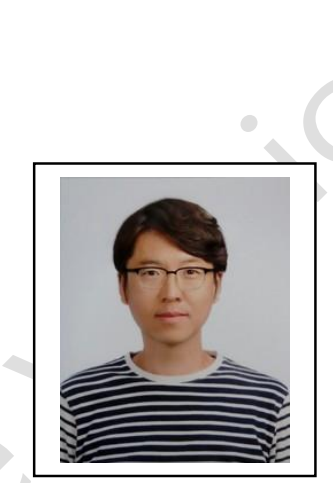

\section{Authors}

\section{Dr. Jung-Hwan Nam}

Agriculture Researcher, Highland Agriculture Research Institute, National Institute of Crop Science Rural Development Administration. 
Changes in $\alpha$-Amylase and Protease activities in Quinoa, Amaranth, and Brown Rice according to Germination Time

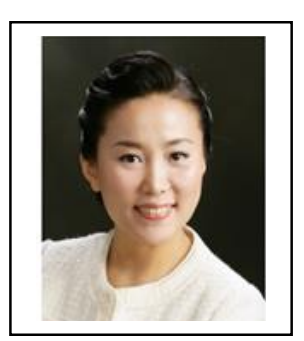

\section{Dr. Soojin Park}

Corresponding author,

Associate professor,

School of Food \& Nutritional Science of Bio-industry, Semyung Univ. 